\title{
Factors Predicting the Presence of Concomitant Enterocele and Rectocele in Female Patients With External Rectal Prolapse
}

\author{
Akira Tsunoda, Tomoko Takahashi, Kenji Sato, Hiroshi Kusanagi \\ Department of Gastroenterological Surgery, Kameda Medical Center, Kamogawa, Japan
}

Purpose: External rectal prolapse (ERP) is frequently associated with other pelvic disorders, such as enterocele, rectocele, and perineal descent. Evacuation proctography makes it possible to visualize the development of such anatomical abnormalities. The aim of this study was to identify the variables that would predict associated abnormalities in patients with ERP.

Methods: Between February 2010 and August 2019, 124 female patients with ERP, who were evaluated using proctography were included in this study. Enterocele was diagnosed when the extension of the loop of the small bowel was located between the vagina and rectum. A significant rectocele was defined as $>20 \mathrm{~mm}$ in diameter. Multivariate analysis was used to establish which morphological parameters best predicted the presence of enterocele or rectocele.

Results: Sixty-five patients had ERP alone, while 59 patients (47.6\%) had additional findings on proctography. The most frequently associated abnormality was enterocele with 48 of the patients (38.7\%) having this condition. Rectocele was detected in 17 of the 124 patients (13.7\%). The median length of the ERP was $30 \mathrm{~mm}$ (range, 7 to $147 \mathrm{~mm}$ ). The results of the stepwise multiple regression analysis showed that a history of hysterectomy and the length of the ERP were significantly associated with the presence of enterocele. The analysis showed that the longer the prolapse, the higher the incidence of enterocele. A history of hysterectomy was also significantly associated with the presence of rectocele. Conclusion: Patients with ERP often have associated anatomical abnormalities and should be investigated thoroughly before planning surgical treatment.

Keywords: External rectal prolapse; Enterocele; Rectocele; Hysterectomy

\section{INTRODUCTION}

External rectal prolapse (ERP) is a circumferential intussusception of the rectal wall with external displacement. It occurs typically in elderly and multiparous women. Patients with ERP have various symptoms such as fecal incontinence (FI), constipation,

Received: May 7, 2020 - Revised: Jul 15, 2020 • Accepted: Jul 16, 2020 Correspondence to: Akira Tsunoda, M.D., Ph.D.

Department of Gastroenterological Surgery, Kameda Medical Center, 929 Higashi-cho, Kamogawa, Chiba 296-8602, Japan

Tel: +81-4-7092-2211, Fax: +81-4-7099-1198

E-mail: tsunoda.akira@kameda.jp

ORCID: https://orcid.org/0000-0002-6211-0219

(C) 2021 The Korean Society of Coloproctology

This is an open-access article distributed under the terms of the Creative Commons Attribution NonCommercial License (https://creativecommons.org/licenses/by-nc/4.0) which permits unrestricted noncommercial use, distribution, and reproduction in any medium, provided the original work is properly cited. mucus discharge, and hemorrhage. Surgery is necessary to eliminate the prolapse and correct associated functional abnormalities. Female patients with ERP are frequently associated with other pelvic disorders, such as enterocele, rectocele, perineal descent, and pelvic organ prolapse (POP) $[1,2]$. However, male patients with ERP are rarely combined with such disorders except for perineal descent. Evaluation of such anatomical abnormalities has previously relied predominantly on physical examination. However, the accuracy of diagnosis is examiner-dependent, which is influenced by clinical experience. In fact, experienced gynecologists, using only physical examination, failed to detect a significant number of radiologically demonstrable enteroceles [3].

Visualization of the anatomical structures and their relationship to each other is possible with radiological examination. Magnetic resonance imaging has limitations because the patient is examined in the supine position which may not be suitable for detect- 
ing ERP. During evacuation proctography the patient is examined in the sitting position, which provides information on different aspects of anorectal and pelvic floor function and offers the possibility of visualizing the development of anorectal anatomical abnormalities [1]. Although proctography was used in patients with defecation disorders $[1,4]$, the significance of associated abnormalities, such as enterocele and rectocele, in selecting the surgical procedure for patients with ERP has not been sufficiently discussed. This study aimed to identify the variables that are predictive of associated anatomical abnormalities in female patients with ERP and to discuss the significance of the abnormalities in selecting the surgical procedure.

\section{METHODS}

Patients seen in the proctology clinic with symptoms of obstructed defecation (OD), FI, or other anorectal symptoms including mucus discharge and overt prolapse of the rectum underwent evacuation proctography. Data for the patients with ERP were prospectively entered into a pelvic floor database. Incontinence severity was documented using the Fecal Incontinence Severity Index (FISI) score [5]. Symptoms of OD were measured using the Constipation Scoring System (CSS) score [6].

This study was approved by the Ethical Committee of Kameda Medical Center (2019-120). Information on the study protocol was made public, and patients were ensured that they could withdraw consent. However, no patients or their relatives subsequently refused to participate in the study.

\section{Evacuation proctography}

The proctography technique was standardized. The small bowel was opacified with a mixture containing 100-mL Barister (barium sulfate 100\% w/w; Fushimi Health Care Ltd., Kagawa, Japan) and 10-mL Urografin (60\% w/w; Bayer Pharmaceutical Ltd., Osaka, Japan), ingested 30 minutes prior to the procedure. The patient was placed in the left lateral position on the fluoroscopic table; barium installation $(50 \mathrm{~mL})$ and air insufflation were performed to improve the quality of the contrast image. A synthetic stool consisting of barium sulfate, porridge oats, and water was inserted into the rectum using a $50-\mathrm{mL}$ bladder syringe. A total of $150 \mathrm{~mL}$ was introduced. The patient was then seated on a radiolucent commode on a fluoroscopic X-ray table. Lateral radiographs of the pelvis in resting, squeezing, and pushing positions were taken. The patient was then asked to bear down maximally during evacuation. Images from proctography were analyzed by one of the authors (TT), who is experienced in this evaluation [7] and was blinded at the time to the symptomatology of the individual patients. Measurements were taken using the X-ray flat panel detector (Toshiba Ultimax, Toshiba Medical Systems, Otawara, Japan) calibrated to a metal globe or a paper clip of known dimensions screened within the image field during proctography.

All measurements were taken from the maximal straining dur- ing defecation. ERP was diagnosed when a circumferential descent of the entire thickness of the rectal wall was seen coming out through the anal verge. Enterocele was diagnosed when the extension of the loop of the small bowel was located between the vagina and rectum [1]. We did not perform a vaginal contrast study and a finding that the small bowel goes down beyond a level of $3 \mathrm{~cm}$ from the anorectal junction was considered to be enterocele, because it is assumed that the normal level of the vaginal vault is in the upper part of the lower third of the rectum, which seems to be at least $>30 \mathrm{~mm}$ from the anorectal angle (anterior rectal wall) [7]. A significant rectocele was defined as $>20 \mathrm{~mm}$ in diameter. Small rectocele $(<20 \mathrm{~mm})$ are common events in healthy volunteers [8] and are often asymptomatic [9]. The size was calculated in a standard fashion in the anterior-posterior dimension by measuring the distance between the most ventral part of the anterior rectal wall and an extrapolated line of the expected portion of the rectal wall [10]. Pelvic floor descent during defecation was estimated by the degree of the anorectal junction in relation to the inferior margin of the ischial tuberosity.

\section{Statistical analysis}

Quantitative data are expressed as the median and range. The analysis was performed using the Mann-Whitney U-test for unpaired data. Correlation between continuous variables was analyzed using Pearson correlation coefficients. Stepwise multiple regression analysis was used to establish which morphological parameters shown by proctography best predicted the presence of enterocele. In the regression analysis, the presence of enterocele was selected as the dependent variable. Independent variables included the presence of rectocele, the length of ERP, and pelvic floor descent. Age, parity, history of surgery for ERP, and history of hysterectomy were analyzed as additional covariates. Similarly, the stepwise multiple regression analysis was also employed to identify the variables predictive of rectocele. A value of $\mathrm{P}<0.05$ was considered as significant for all tests. The data were analyzed by using the software package of SPSS ver. 11.0 for Windows (SPSS Japan Inc., Tokyo, Japan).

\section{RESULTS}

\section{Demographic and clinical findings}

Between February 2010 and August 2019, 817 patients underwent evacuation proctography, and 155 (19.0\%) were found to have ERP. Of these, 124 (80.0\%) were women and were included in this study. Their median age was 80 years (range, 34 to 94 years). Six had OD alone, while 116 had FI (60 with FI alone, and 56 with FI and OD). Two had mucus discharge alone. The median FISI score was 37 (range, 0 to 61), and the median CSS score was 9 (range, 0 to 19$)$. Of the 124 patients, $110(88.7 \%)$ underwent surgery for ERP including laparoscopic ventral rectopexy (LVR) $(n=79)$, Delorme procedure $(n=17)$, Altemeier procedure $(n=1)$, and LVR with sacrocolpopexy for coexisting ERP and POP $(n=13)$. There 
was no mortality and no significant morbidity postoperatively. Ten patients had undergone previous surgery for ERP including Delorme procedure $(n=6)$, Gant-Miwa procedure $(n=2)$, Altemeier procedure $(n=1)$, and abdominal suture rectopexy $(n=1)$. Fifty-five patients (44.4\%) had undergone other pelvic surgeries, including hysterectomy $(n=20)$, transvaginal surgery for POP $(n=9)$, oophoron-salpingectomy $(n=3)$, surgery for imperforate anus $(n=1)$, total cystectomy $(n=1)$, and sacral nerve modulation $(\mathrm{n}=1)$.

\section{Evacuation proctography}

Sixty-five patients had ERP alone, while 59 patients (47.6\%) had additional findings on proctography (Table 1). The most frequently associated abnormality was enterocele (48/124, 38.7\%). In

Table 1. Evacuation proctography in patients with external rectal prolapse (ERP)

\begin{tabular}{lc}
\hline Finding & No. of patients \\
\hline ERP alone & 65 \\
ERP + additional abnormalities & 59 \\
$E R P+E C$ & 39 \\
$E R P+R C$ & 9 \\
$E R P+S C$ & 2 \\
ERP + EC+RC & 8 \\
ERP + EC+SC & 1 \\
Total & 124 \\
\hline
\end{tabular}

$\mathrm{EC}$, enterocele; $\mathrm{RC}$, rectocele; SC, sigmoidocele.

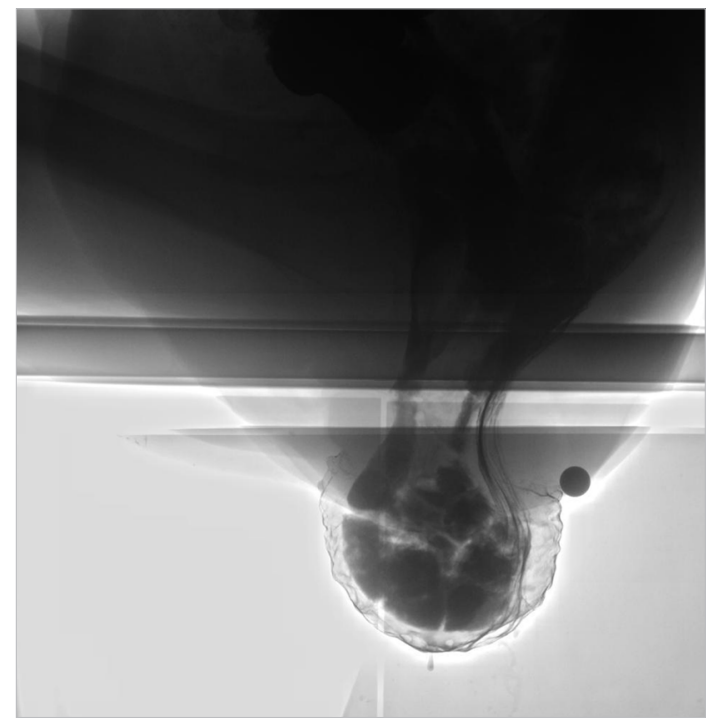

Fig. 1. External rectal prolapse with enterocele shown by proctography in an 80-year-old female patient. Small intestine advanced into external rectal prolapse.
26 patients (54.2\%) the small intestine advanced into ERP (Fig. 1). Rectocele was detected in 17 of the 124 patients (13.7\%) (Fig. 2). The frequency of additional findings was significantly higher in patients with hysterectomy than in patients without (15/20 vs. $44 / 104, \mathrm{P}=0.013$ ). The length of ERP was $30 \mathrm{~mm}$ (range, 7 to 147 $\mathrm{mm}$ ), the size of rectocele was $29 \mathrm{~mm}$ (range, 21 to $45 \mathrm{~mm}$ ), and pelvic floor descent was $25 \mathrm{~mm}$ (range, -9 to $61 \mathrm{~mm}$ ).

Table 2 shows the demographic and additional findings in patients compared to the length of ERP. The incidence of enterocele was significantly higher in patients with a longer prolapse $(>30$ $\mathrm{mm}, 52.6 \%)$ than those with a shorter prolapse $(\leq 30 \mathrm{~mm})$

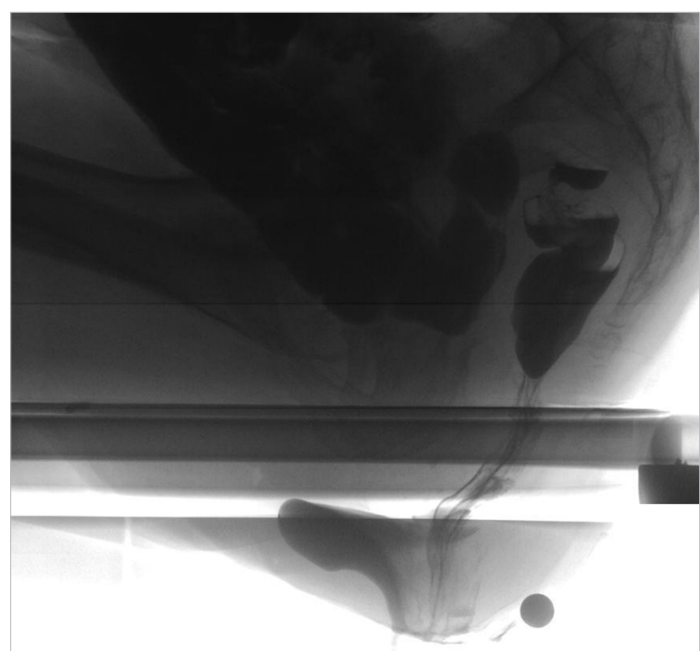

(A)

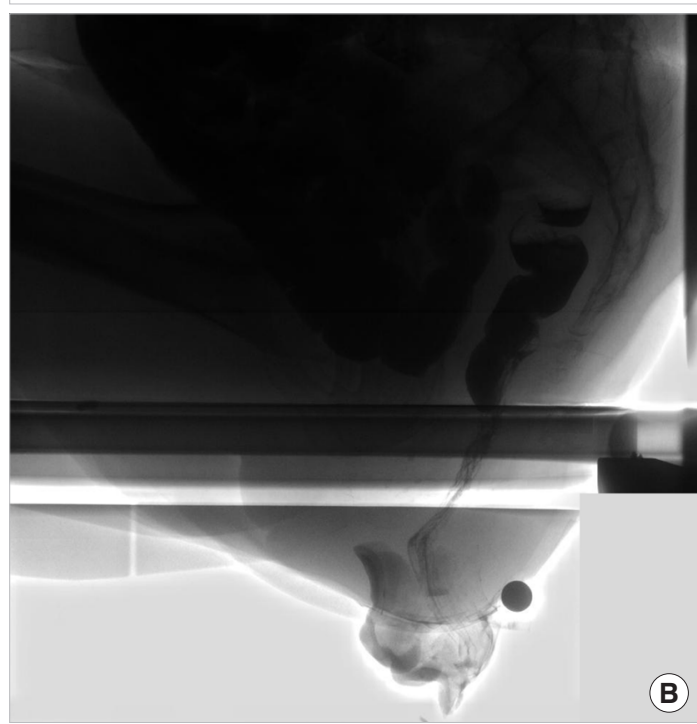

Fig. 2. External rectal prolapse with rectocele shown by proctography in an 80-year-old female patient. (A) On straining down, rectocele developed. (B) On continued straining, the apex of the intussusception passed through the anus and external rectal prolapse developed. 
Table 2. Demographic and anatomical findings in patients with external rectal prolapse (ERP)

\begin{tabular}{|c|c|c|c|}
\hline \multirow{2}{*}{ Variable } & \multicolumn{2}{|c|}{ Length of ERP } & \multirow{2}{*}{ P-value } \\
\hline & $\leq 30 \mathrm{~mm}(\mathrm{n}=67)$ & $>30 \mathrm{~mm}(\mathrm{n}=57)$ & \\
\hline Age (yr) & 80 (34-95) & $79(45-91)$ & 0.373 \\
\hline Parity & $2(0-5)$ & $2(0-5)$ & 0.082 \\
\hline Previous hysterectomy & $10(14.9)$ & $10(17.5)$ & 0.693 \\
\hline Previous surgery for ERP & $6(9.0)$ & $4(7.0)$ & 0.752 \\
\hline Enterocele & $18(26.9)$ & $30(52.6)$ & 0.003 \\
\hline Rectocele, $>20 \mathrm{~mm}$ & $10(14.9)$ & $7(12.3)$ & 0.670 \\
\hline Sigmoidocele & $1(1.5)$ & $2(3.5)$ & 0.594 \\
\hline Pelvic floor descent ${ }^{a}(\mathrm{~mm})$ & $25.2(-8.8$ to 54.6$)$ & $24.3(-8.7$ to 60.8$)$ & 0.821 \\
\hline
\end{tabular}

Values are presented as median (range) or number (\%).

The extent of the anorectal junction relative to the inferior margin of the ischial tuberosity during defecation.

Table 3. Pearson correlation coefficients between the presence of enterocele and variables

\begin{tabular}{lcc}
\hline Variable & Coefficients & P-value \\
\hline Age (yr) & 0.088 & 0.332 \\
Parity & -0.040 & 0.658 \\
Previous hysterectomy (no, yes) & 0.327 & $<0.0001$ \\
Previous surgery for ERP (no, yes) & -0.175 & 0.052 \\
Rectocele, > 20 mm (no, yes) & 1.90 & 0.034 \\
Sigmoidocele (no, yes) & -0.017 & 0.848 \\
Length of ERP, > 30 mm (no, yes) & 0.264 & 0.003 \\
Pelvic floor descent (mm) & 0.041 & 0.658 \\
\hline
\end{tabular}

ERP, external rectal prolapse.

(26.9\%). There was no significant difference in age, parity, the history of previous hysterectomy, the history of previous surgery for ERP, the presence of enterocele, the presence of sigmoidocele, and the pelvic floor descent between the groups, respectively. Enterocele was detected in 8 of 10 patients $(80.0 \%)$ with longer prolapse who had a history of hysterectomy.

\section{Pearson correlation coefficients}

The correlation between the presence of enterocele, demographic findings, and morphological parameters are shown in Table 3. A history of hysterectomy, the presence of rectocele, and the longer length of ERP were significantly associated with the presence of enterocele. The correlation between the presence of rectocele and other variables are shown in Table 4. A history of hysterectomy and the presence of enterocele were significantly associated with the presence of rectocele.

\section{Regression analysis}

The results of the stepwise multiple regression analysis that in-
Table 4. Pearson correlation coefficients between the presence of rectocele and variables

\begin{tabular}{lcc}
\hline Variable & Coefficients & P-value \\
\hline Age (yr) & -0.147 & 0.102 \\
Parity & 0.017 & 0.848 \\
Previous hysterectomy (no, yes) & 0.192 & 0.032 \\
Previous surgery for ERP (no, yes) & -0.088 & 0.333 \\
Enterocele (no, yes) & 0.190 & 0.034 \\
Sigmoidocele (no, yes) & -0.047 & 0.607 \\
Length of ERP, > 30 mm (no, yes) & -0.038 & 0.673 \\
Pelvic floor descent (mm) & 0.077 & 0.411 \\
\hline
\end{tabular}

ERP, external rectal prolapse.

Table 5. The results of multiple regression analysis

\begin{tabular}{lcccc}
\hline Variable & $\begin{array}{c}\text { Unstandardized } \\
\text { regression } \\
\text { weight }\end{array}$ & t-value & P-value $\begin{array}{c}\text { Variance } \\
\text { explained } \\
(\%)\end{array}$ \\
\hline Enterocele & & & & \\
Previous hysterectomy (no, yes) & 0.394 & 3.40 & 0.001 & \\
$\begin{array}{l}\text { Length of ERP, }>30 \mathrm{~mm} \text { (no, yes) } \\
\text { Rectocele }\end{array}$ & 0.267 & 3.17 & 0.002 & 16 \\
Previous hysterectomy (no, yes) & 0.162 & 2.29 & 0.024 & 4 \\
\hline
\end{tabular}

ERP, external rectal prolapse.

cluded demographic and morphological variables are shown in Table 5. A history of hysterectomy and the length of ERP were significantly associated with the presence of enterocele, i.e., the longer the prolapse, the higher the incidence of enterocele. A history of hysterectomy was also significantly associated with the presence of rectocele.

\section{DISCUSSION}

This study demonstrated that a history of hysterectomy and a longer length of ERP were predictive of the presence of enterocele. Previous hysterectomy also increased the risk of rectocele. To our knowledge, no study has identified the variables predictive of enterocele or rectocele in female patients with ERP using a multivariate analysis. The incidence of enterocele in patients with ERP was $38.7 \%(48 / 124)$ in this study. Previous studies showed that the incidence was $44.5 \%(165 / 371)$ to $46.9 \%(23 / 49)$ [1, 9 , 11]. Conversely, Mellgren et al. [12] reported that $37.7 \%(26 / 69)$ of the patients with enterocele on proctography had concomitant ERP. Thirty-one male patients were excluded from the analyses, because male patients are rarely combined with enterocele or rectocele.

A history of hysterectomy predisposed to the presence of enterocele in patients with defecation disorders $[12,13]$. This is consis- 


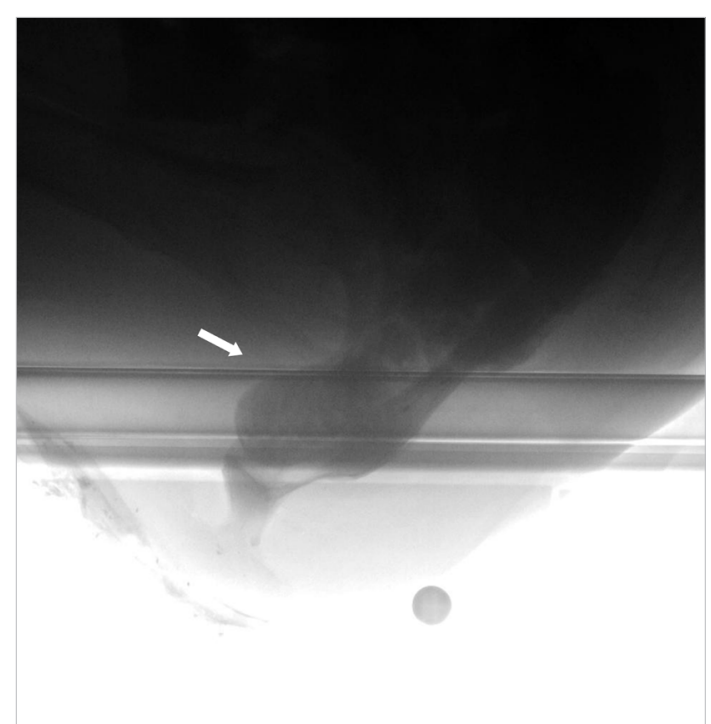

Fig. 3. Enterocele shown by proctography in a 75-year-old female patient. Small intestine advanced between the vagina and rectum during straining (arrow). She had the symptoms of obstructed defecation after having previous suture rectopexy for external rectal prolapse.

tent with our findings in the patients with ERP. Hysterectomy may lead to a possible iatrogenic disruption of vaginal supportive tissue, which causes a change in vaginal axis or loss of continuity of fibrous connective tissue [14]. The correlation between the length of ERP and the presence of enterocele has not been reported previously. When the development of ERP is studied by evacuation proctography, ERP is preceded by a rectal intussusception during straining. The rectal intussusception and ERP contain a peritoneal pouch formed by the anterior rectal wall proximal to the peritoneal reflection [2]. This pouch should be deep in patients with a longer length of ERP and the small intestine may enter the pouch easily, especially in those with a history of hysterectomy. A similar finding was reported from the gynecological field, where there was a positive correlation between the amount of uterine sagging and the severity of enterocele [15]. The etiology of rectocele is multifactorial and risk factors may include vaginal delivery, obesity, advanced age, and chronic straining [16]. Hysterectomy is also considered a risk factor for rectocele development $[17,18]$, and this was in line with our findings in patients with ERP.

The symptoms resulting from enterocele are poorly understood. Typically, females with enterocele may report vaginal bulge, pelvic pressure, or a dragging sensation in the pelvis, especially when standing or bearing down [7]. Pelvic pain may occur because the pull of gravity stretches the mesentery of the contents of the pouch. Since these symptoms, except vaginal protrusion, may occur in patients with isolated ERP, it is not easy to clarify whether the symptoms are derived from isolated ERP or combined enterocele with ERP. The role of enterocele as a cause of OD is unclear and the patients with enterocele often have a combination of dif- ferent abnormalities $[14,19]$. In fact, the patients with ERP frequently reported OD irrespective of concomitant enterocele [20].

Evacuation proctography plays a useful role in detecting enterocele or rectocele prior to surgery for ERP. There is a controversy concerning, whether or not the discovery of additional anatomical abnormalities, such as enterocele and rectocele, in patients with vaginal prolapse and/or defecation disorders is meaningful because it is uncertain whether these defects contribute to clinical symptoms [21]. This argument may be applied to the patients with ERP that is associated with enterocele or rectocele. Nevertheless, it has not been sufficiently discussed whether the surgical procedure should be selected based on these findings in patients with ERP. Previous studies reported that enterocele is often associated with other concomitant pelvic disorders, and possible concurrent pathology must be considered before planning treatment $[12,15,21]$. The treatment of ERP seems to be given priority over the associated abnormalities. Perineal procedures such as Delorme procedure or rectosigmoidectomy, and posterior rectopexy such as suture rectopexy, posterior mesh rectopexy, or resection rectopexy does not eliminate the rectovaginal pouch. Hence, the associated enterocele or rectocele is not corrected, and symptoms such as vaginal bulge, pressure in the vagina, or constipation may persist postoperatively. In fact, we encountered such a case of woman who previously underwent suture rectopexy for ERP but reported OD postoperatively. Enterocele was detected by conducting a proctography examination (Fig. 3). The patient underwent LVR for enterocele with a significant improvement in her OD symptoms postoperatively (the OD syndrome score validated by Altomare et al. [22] was 12 preoperatively vs. 6 at 12 months postoperatively). Additionally, rectal perforation with evisceration of the small bowel through the anus may be a potential risk [23, 24].

The selection of perineal procedures for high-risk patients with ERP is totally reasonable [25]. After surgery, the possible persistent symptoms caused by combined other abnormalities such as rectocele or enterocele can be treated with biofeedback or medications. However, if laparoscopic procedures are selected for the treatment of ERP, the possible concurrent enterocele or rectocele should be considered when planning the specific techniques. Ventral rectopexy obliterates the rectovaginal pouch and reinforces the rectovaginal septum, which can correct enterocele and rectocele. Proctography performed before and 6 months after LVR in patients with ERP in our previous study showed that enterocele disappeared in all patients affected and the size of rectocele was significantly reduced postoperatively [20]. Rectocele abnormalities did not disappear completely because the distal part of the rectocele cannot be corrected by LVR. Mege et al. [26] reported that one of the predictive factors for long-term failure in patients who undergo LVR for enterocele was concomitant rectocele, which might not have been eliminated, and thus, constipation persisted postoperatively. A large rectocele may be corrected by a combination of transvaginal posterior colporrhaphy and LVR $[27,28]$. LVR for ERP has a further advantage when it is used in 
conjunction with sacrocolpopexy applied to POP. We reported such an experience previously [29].

Certainly, this study has its limitations. First, this was a retrospective study of prospectively collected data. Second, accurate images of rectocele on proctography may not have been obtained in our patients. To detect a rectocele on the proctography correctly, patients should have a satisfactory sphincter mechanism in order to allow increasing intrarectal pressure during straining. Yet, the patients with ERP often had lax sphincters and therefore possible rectoceles might not be have been detected. Further, a synthetic stool inserted into the rectum sometimes flows backward, and thus, not enough material could have been present to detect a rectocele in certain cases. Third, although one of the authors (TT) was experienced in the detection of enterocele during proctography [7], the exact site of the small bowel between the vagina and rectum was not imaged because we did not perform a vaginal contrast study. This might have led to misdiagnosis of enterocele.

Evacuation proctography improves diagnostic accuracy and helps to identify additional abnormalities (including enterocele or rectocele) prior to surgery for ERP. Evacuation proctography can assist in the planning of the operative approach for each patient. Failure to recognize and repair these anatomical abnormalities at the time of surgery may lead to persistent symptomatology.

In conclusion, previous hysterectomy increases the risk of enterocele or rectocele in female patients with ERP. A longer length of ERP also increases the risk of enterocele. Patients with ERP often have such anatomical abnormalities and should be investigated thoroughly before planning surgical treatment, especially in those with previous hysterectomy. Further studies are required on the significance of associated abnormalities in selecting the surgical procedure for patients with ERP.

\section{CONFLICT OF INTEREST}

No potential conflict of interest relevant to this article was reported.

\section{ACKNOWLEDGMENTS}

The authors thank Yuko Tsunoda for her assistance with the statistical analysis.

\section{REFERENCES}

1. Mellgren A, Bremmer S, Johansson C, Dolk A, Uden R, Ahlback SO, et al. Defecography: results of investigations in 2,816 patients. Dis Colon Rectum 1994;37:1133-41.

2. Broden B, Snellman B. Procidentia of the rectum studied with cineradiography: a contribution to the discussion of causative mechanism. Dis Colon Rectum 1968;11:330-47.

3. Kelvin FM, Maglinte DD, Hornback JA, Benson JT. Pelvic pro- lapse: assessment with evacuation proctography (defecography). Radiology 1992;184:547-51.

4. Agachan F, Pfeifer J, Wexner SD. Defecography and proctography: results of 744 patients. Dis Colon Rectum 1996;39:899-905.

5. Rockwood TH, Church JM, Fleshman JW, Kane RL, Mavrantonis C, Thorson AG, et al. Patient and surgeon ranking of the severity of symptoms associated with fecal incontinence: the fecal incontinence severity index. Dis Colon Rectum 1999;42:1525-32.

6. Agachan F, Chen T, Pfeifer J, Reissman P, Wexner SD. A constipation scoring system to simplify evaluation and management of constipated patients. Dis Colon Rectum 1996;39:681-5.

7. Takahashi T, Yamana T, Sahara R, Iwadare J. Enterocele: what is the clinical implication? Dis Colon Rectum 2006;49(10 Suppl): S75-81.

8. Shorvon PJ, McHugh S, Diamant NE, Somers S, Stevenson GW. Defecography in normal volunteers: results and implications. Gut 1989;30:1737-49.

9. Mercer-Jones MA, Sprowson A, Varma JS. Outcome after transperineal mesh repair of rectocele: a case series. Dis Colon Rectum 2004;47:864-8.

10. Bartram CI, Turnbull GK, Lennard-Jones JE. Evacuation proctography: an investigation of rectal expulsion in 20 subjects without defecatory disturbance. Gastrointest Radiol 1988;13:72-80.

11. Jarrett ME, Wijffels NA, Slater A, Cunningham C, Lindsey I. Enterocoele is a marker of severe pelvic floor weakness. Colorectal Dis 2010;12:e158-62.

12. Mellgren A, Johansson C, Dolk A, Anzen B, Bremmer S, Nilsson BY, et al. Enterocele demonstrated by defaecography is associated with other pelvic floor disorders. Int J Colorectal Dis 1994;9:1214.

13. Kelvin FM, Hale DS, Maglinte DD, Patten BJ, Benson JT. Female pelvic organ prolapse: diagnostic contribution of dynamic cystoproctography and comparison with physical examination. AJR Am J Roentgenol 1999;173:31-7.

14. Chou Q, Weber AM, Piedmonte MR. Clinical presentation of enterocele. Obstet Gynecol 2000;96:599-603.

15. Ranney B. Enterocele, vaginal prolapse, pelvic hernia: recognition and treatment. Am J Obstet Gynecol 1981;140:53-61.

16. Hendrix SL, Clark A, Nygaard I, Aragaki A, Barnabei V, McTiernan A. Pelvic organ prolapse in the Women's Health Initiative: gravity and gravidity. Am J Obstet Gynecol 2002;186:1160-6.

17. DeLancey JO. Anatomic aspects of vaginal eversion after hysterectomy. Am J Obstet Gynecol 1992;166 (6 Pt 1):1717-28.

18. Smart NJ, Mercer-Jones MA. Functional outcome after transperineal rectocele repair with porcine dermal collagen implant. Dis Colon Rectum 2007;50:1422-7.

19. Holley RL. Enterocele: a review. Obstet Gynecol Surv 1994;49: 284-93.

20. Tsunoda A, Takahashi T, Ohta T, Fujii W, Kusanagi H. New-onset rectoanal intussusception may not result in symptomatic improvement after laparoscopic ventral rectopexy for external rectal prolapse. Tech Coloproctol 2016;20:101-7. 
21. Altringer WE, Saclarides TJ, Dominguez JM, Brubaker LT, Smith CS. Four-contrast defecography: pelvic "floor-oscopy". Dis Colon Rectum 1995;38:695-9.

22. Altomare DF, Spazzafumo L, Rinaldi M, Dodi G, Ghiselli R, Piloni V. Set-up and statistical validation of a new scoring system for obstructed defaecation syndrome. Colorectal Dis 2008;10:84-8.

23. Hultgren T. Spontaneous rupture of the rectum with evisceration of small intestine through the anus: a case report. Acta Chir Scand 1986;152:239-40.

24. De Vogel PL, Kamstra PE. Rupture of the rectum with evisceration of small intestine through the anus: a complication of advanced rectal prolapse. Case report. Eur J Surg 1994;160:187-8.

25. Yoon SG. Rectal prolapse: review according to the personal experience. J Korean Soc Coloproctol 2011;27:107-13.

26. Mege D, Sans A, Maignan A, Duclos J, Frasconi C, Le Huu Nho R, et al. Temporary successful results of ventral rectopexy for en- terocele surgical correction, about 138 patients. Int J Colorectal Dis 2017;32:1569-75.

27. D’Hoore A, Vanbeckevoort D, Penninckx F. Clinical, physiologi$\mathrm{cal}$ and radiological assessment of rectovaginal septum reinforcement with mesh for complex rectocele. Br J Surg 2008;95:126472.

28. Van der Hagen SJ, van Gemert WG, Soeters PB, de Wet H, Baeten CG. Transvaginal posterior colporrhaphy combined with laparoscopic ventral mesh rectopexy for isolated Grade III rectocele: a prospective study of 27 patients. Colorectal Dis 2012;14:1398402.

29. Kiyasu Y, Tsunoda A, Takahashi T, Nomura M. Laparoscopic ventral rectopexy with sacrocolpopexy for coexisting pelvic organ prolapse and external rectal prolapse. J Anus Rectum Colon 2018; 1:141-6. 